\title{
An Analysis of Utility Based Estimates of Fiscal Capacity \#
}

\author{
Joseph A. Ziegler and J. Martin Redfern*
}

During the past two decades there have been many attempts to estimate fiscal capacity of state and local governments. Personal income is used often as a measure of fiscal capacity by the federal government for grant programs intended to provide equalization. Its use is justified on the basis that state and local government revenues are collected ultimately from current income. At the subnational level, however, this approach ignores the abilities of local governments to export taxes. Moreover, personal income as well as other income measures which are used by the federal government for grant allocations, e.g., money income, adjusted gross income, taxable income, and income by place of work, tend to understate income in the traditional accretion sense, i.e., as increases in net wealth. They do not include, for example, items such as unrealized property and imputed income which are necessary to derive truly comprehensive estimates of income. Each of these measures are based on a different definition which generate significant variations in fiscal capacity estimates. ${ }^{1}$ The choice of an appropriate income measure is difficult because none of the measures is based on a comprehensive income concept.

The Advisory Commission on Intergovernmental Relations suggests the use of its Representative Tax System (RTS) which estimates tax capacity as the amount of revenue each state would raise if identical, i.e., national average tax rates are used. ${ }^{2}$ In essence it defines fiscal capacity in terms of the average behavior of the taxing units which results in estimates which are less than actual tax collections for units which tax at rates exceeding the average. The RTS considers neither the interrelated nature of tax bases, i.e., that the ability to tax a given base (such as property) will be affected by the size of another base (such as income), nor the interactions among the various tax bases and rates within a given taxing unit. ${ }^{3}$

More recent studies have used regression analysis to improve the conceptual shortcomings of the A.C.I.R. methodology. ${ }^{4}$ They have estimated fiscal capacity of individual taxing units as the expected tax collections from residents and nonresidents, i.e., the amount of tax revenue a unit could collect if its behavior was not unlike the average of all units subject to

\#The authors would like to thank an anonymous referee for suggestions but of course the usual caveat applies. Published with the approval of the Director of the Arkansas Agricultural Experiment Station.

*Professor of Economics and Professor of Agricultural Economics, respectively, University of Arkansas. 
analysis. In effect, these studies attempt to allow for patterns of interactions of tax bases in a unit as reflected in actual taxing experience. The resulting estimates, while different from those of the ACIR, are also less than actual tax collections for some jurisdictions.

The term "capacity" as used in these previously cited studies has not meant as absolute upper bound on tax collections but only potential collections if all units behaved as the "average" in some sense. Strictly speaking, "capacity" implies some maximum; in particular, to speak of the fiscal capacity of a state or local government implies that each has a maximum limit to its taxing ability. As such, it can be thought of in the more traditional context of a budget constraint where the budget will be allocated between public and private expenditures. In a recent study, points on this constraint were estimated in terms of levels of utility achieved with various mixes of public and private expenditures. ${ }^{5}$ Because it focuses on estimates of utility, this innovative approach changes the emphasis of the fiscal capacity debate from an exercise in the ad hoc prediction of tax revenues to an analysis of the potential welfare effects of various tax and expenditure policies. Fiscal capacity estimates are used currently in various equity oriented federal programs to redistribute money to those jurisdictions with smaller capacities to raise their own money. But the use of more traditional estimates of fiscal capacity can result in greater inequities among the jurisdictions, not less. ${ }^{6}$ The utility based estimates presumably are an improvement in estimating fiscal capacities which could be used in equity oriented policies. It is the purpose of this paper to analyze the appropriateness of this methodology for use in such policies.

\section{DESCRIPTION OF THE UTILITY BASED ESTIMATES ${ }^{7}$}

It is assumed that each state has an identical utility function of the form:

$$
\mathrm{U}=\mathrm{u}(\mathrm{R}, \mathrm{G})
$$

where $\mathbf{R}=$ private goods and services, and

$\mathrm{G}=$ public goods and services,

which is maximized subject to a budget or fiscal constraint of the form:

$$
(F C)_{j}=P_{G} G+P_{R} R=\sum_{i=1}^{m} I_{i j}+S_{j}
$$

where $(\mathrm{FC})_{\mathrm{j}}=$ fiscal constraint of state $\mathrm{j}$,

$\mathrm{P}_{\mathrm{G}}=$ price of public goods,

$\mathrm{P}_{\mathrm{R}}=$ price of private goods,

$\mathrm{G}=$ quantity of public goods,

$\mathrm{R}=$ quantity of private goods,

$I_{i j}=$ income of resident $i$ of state $j$,

$S_{j}=$ taxes shifted out of $j$.

For purposes of estimation it is assumed that the utility level attained by any given citizen is representative of that attained by other members of the 
TABLE 1

Alternative Fiscal Capacity Indexes and Rankings

\begin{tabular}{|c|c|c|}
\hline States & $\begin{array}{l}\text { Utility Based } \\
\text { Estimate }^{\mathrm{a}}\end{array}$ & $\begin{array}{l}\text { Conventional } \\
\text { Estimate }^{\mathrm{b}}\end{array}$ \\
\hline Alabama & 16 & 49 \\
\hline Alaska & 40 & 8 \\
\hline Arizona & 50 & 33 \\
\hline Arkansas & 46 & 48 \\
\hline California & 51 & 4 \\
\hline Colorado & 5 & 21 \\
\hline Connecticut & 22 & 2 \\
\hline Delaware & 10 & 6 \\
\hline District of Columbia & 49 & 1 \\
\hline Florida & 47 & 31 \\
\hline Georgia & 8 & 42 \\
\hline Hawaii & 3 & 14 \\
\hline Idaho & 18 & 38 \\
\hline Illinois & 29 & 4 \\
\hline Indiana & 10 & 16 \\
\hline Iowa & 12 & 15 \\
\hline Kansas & 4 & 20 \\
\hline Kentucky & 45 & 44 \\
\hline Louisiana & 31 & 44 \\
\hline Maine & 37 & 40 \\
\hline Maryland & 6 & 13 \\
\hline Massachusetts . & 13 & 12 \\
\hline Michigan & 41 & 11 \\
\hline Minnesota & 28 & 25 \\
\hline Mississippi & 25 & 57 \\
\hline Missouri & 24 & 27 \\
\hline Montana & 21 & 28 \\
\hline Nebraska & 34 & 18 \\
\hline Nevada & 20 & 3 \\
\hline New Hampshire & 2 & 23 \\
\hline New Jersey & 23 & 9 \\
\hline New Mexico. & 36 & 41 \\
\hline New York & 44 & 7 \\
\hline North Carolina & 48 & 43 \\
\hline North Dakota. & 39 & 30 \\
\hline Ohio & 7 & 16 \\
\hline Oklahoma & 13 & 36 \\
\hline Oregon & 42 & 21 \\
\hline Pennsylvania & 35 & 24 \\
\hline Rhode Island & 30 & 19 \\
\hline South Carolina. & 19 & 50 \\
\hline South Dakota & 27 & 34 \\
\hline Tennessee & 43 & 46 \\
\hline Texas & 13 & 36 \\
\hline Utah & 9 & 38 \\
\hline
\end{tabular}


TABLE 1 (Cont.)

\begin{tabular}{lcc}
\hline \multicolumn{1}{c}{ States } & $\begin{array}{c}\text { Utility Based } \\
\text { Estimate }^{\mathrm{a}}\end{array}$ & \begin{tabular}{c} 
Conventional $_{\text {Estimate }^{\mathrm{b}}}$ \\
\hline Vermont
\end{tabular} \\
Virginia. & 26 & 34 \\
Washington & 33 & 32 \\
West Virginia & 32 & 10 \\
Wisconsin & 38 & 47 \\
Wyoming & 17 & 29 \\
\hline
\end{tabular}

Sources:

a John S. Akin, "Estimates of State Resource Constraints Derived From a Specific Utility Function: An Alternative Measure of Fiscal Capacity,"National Tax Journal, (March, 1979).

bohn S. Akin, "Fiscal Capacity and the Estimation Method of the Advisory Commission on Intergovernmental Relations," National Tax Joumal, (June, 1973).

community and that the utility function is in the direct additive logarithmic or addilog form:

$$
\mathrm{U}\left(\frac{\mathrm{M}}{\mathrm{P}}\right)=\mathrm{a}_{1}\left(\frac{\mathrm{M}}{\mathrm{P}_{1}}\right) \mathrm{b}_{1}+\mathrm{a}_{2}\left(\frac{\mathrm{M}}{\mathrm{P}_{2}}\right) \mathrm{b}_{2}
$$

and can be estimated as:

$$
\begin{aligned}
(\log \text { GEX }-\log \text { PEX }) & =\log a_{1} b_{1}-\log a_{2} b_{2}+b_{1} \log \left(M / P_{1}\right) \\
& -b_{2} \log \left(M / P_{2}\right)+c_{1} Z
\end{aligned}
$$

where GEX = expenditures on public goods per capita = public expenditures of state and local governments per capita,

PEX $=$ expenditures on private goods per capita $=$ (median family income/4) - average tax bill for state,

$\mathrm{M}=$ total governmental plus private expenditure per capita = GEX + PEX,

$\mathrm{P}_{1}=$ price of a unit of public goods in the state = average government wage in state,

$\mathrm{P}_{2}=$ price of a unit of composite private goods bundle in the state $=$ median gross rent, and

$\mathrm{Z}=\mathrm{a}$ vector of state characteristics

The expenditure equation is estimated using ordinary least squares regression on 1969 data for the United States. The terms $a_{1}, b_{1}$, and $b_{2}$ are computed from these coefficients. The coefficients are fit back into the indirect addilog utility function to generate:

$$
\mathrm{U}^{*}=100\left(\frac{\mathrm{M}}{\mathrm{P}_{1}}\right) \cdot 7113+6.7\left(\frac{\mathrm{M}}{\mathrm{P}_{2}}\right) \cdot .042
$$

The resulting utility based estimates of fiscal capacity for each state are shown in Column 1 of Table 2. These estimates are not measures of fiscal capacity in the traditional sense but rather "... that level of estimated 
aggregate utility that can be attained by the jurisdiction through combined private and public expenditure." 8 The use of the utility based estimates of fiscal capacity results in relative rankings which are quite different from those using the more traditional concept. For example, the rank correlation between the utility based estimates and one alternative set of rankings (Table 1) is 0.11 which is not significantly different from zero at the 0.05 level. ${ }^{9}$ Some states which previously were considered to have relatively high fiscal capacities such as California and New York are ranked very low using the utility based estimates, i.e., 51 and 44 respectively, while other states previously ranked low, such as Georgia and Wyoming, are ranked 8 and 1 respectively.

\section{ANALYSIS OF UTILITY BASED ESTIMATES}

While we do not necessarily agree with previous attempts to estimate fiscal capacity, we think that such a radical departure from conventional practices demands analysis. In particular, we propose that this methodology can result in fiscal capacity estimates which are not indicative of relative measures of aggregate utility and, consequently, not suitable for use in equity oriented policies.

The utility based estimates are based on the assumption that each state faces an identical utility function. If this assumption is realized differences in the estimates between states might reflect differences in resources available to them, e.g., differences in income, wealth, or ability to shift taxes outside of the state, or differences in the relative prices of public and private goods. If different preferences are allowed, however, the differences in the estimates cannot be attributed solely to resource constraints which means that fiscal capacity estimates derived from identical price and expenditure information might be different. ${ }^{10}$

Even if one is willing to accept the assumption of identical utility functions, the use of the indirect additive logarithmic utility function to estimate fiscal capacity necessitates the further assumption that this utility function is maximized subject to a resource constraint. If, and only if, this assumption is realized do the resulting estimates of utility levels become estimates of ". . . aggregate utility that can be attained by the jurisdiction ..." and, hence, fiscal capacity measures. If utility is not maximized, however, these estimates may be biased and misleading. For example, if we use the utility based methodology and assume for the moment that the utility function is maximized, we would obtain an estimate of utility (and fiscal capacity) corresponding to $\mathrm{U}_{1}$ at point $\mathrm{A}$ in Figure 1 . In this case utility, and hence fiscal capacity, could be increased only by shifting the resource constraint in some manner, e.g., through direct grants and/or by lowering the relative price of public goods. However, if we use this same methodology but now assume that utility is not maximized, we would obtain an estimate of utility which might, for example, correspond to $\mathrm{U}_{2}$ at point $A$. In this case the estimate of " . . . aggregate utility that can be attained by the jurisdiction ..." is understated. Consequently, absolute 


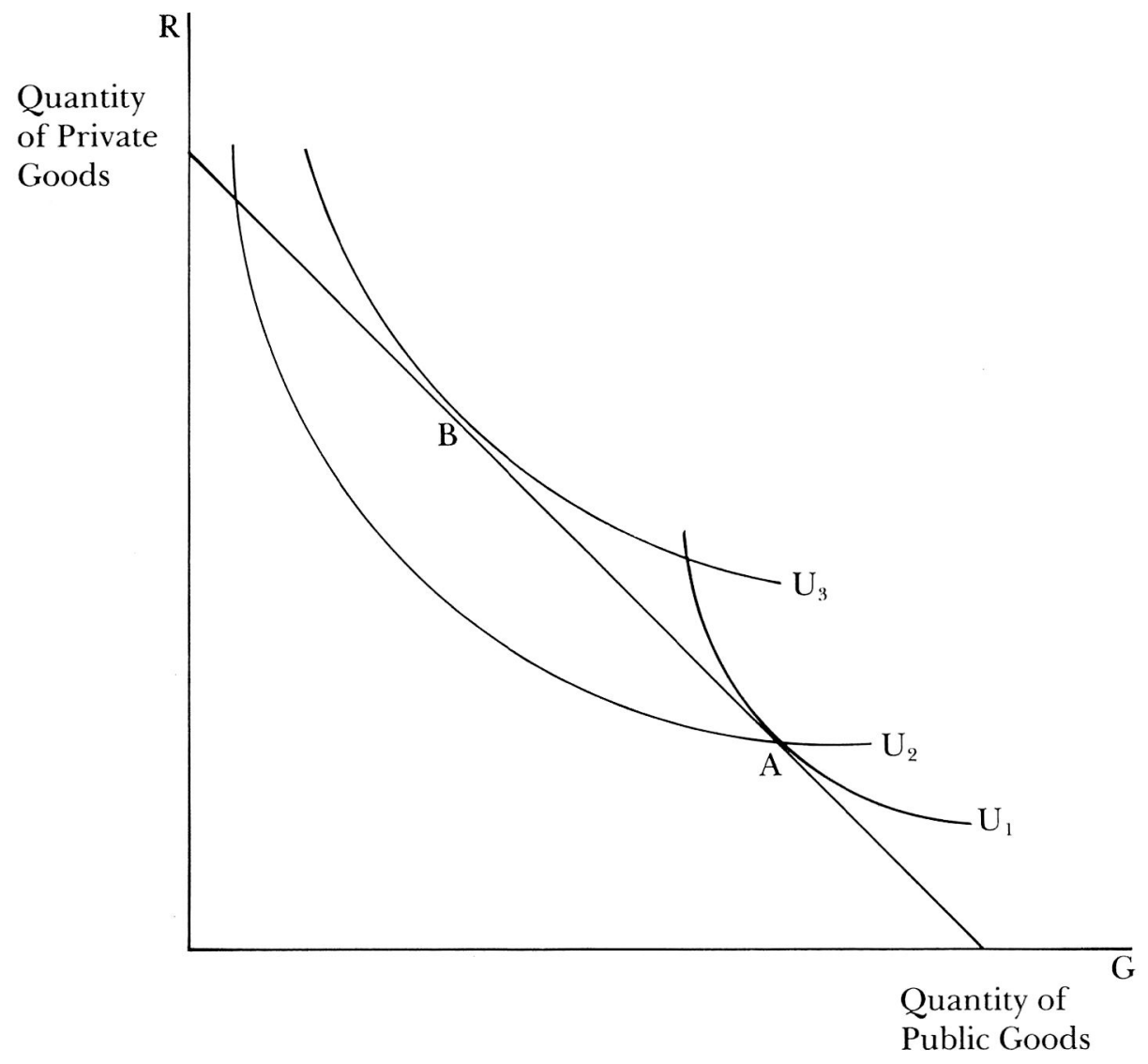

Figure 1

estimates of fiscal capacity are biased to the extent that the implicit assumption of utility maximization is not realized. Moreover, relative estimates, which might be more important from a policy perspective, also are biased to the extent that there are varying degrees of suboptimal behavior among the jurisdictions. Unfortunately, the question of whether, or to what extent, utility is maximized cannot be discerned from this methodology which implicitly assumes that governmental areas do, in fact, maximize utility.

If varying degrees of suboptimal behavior exist among the states the use of utility based fiscal capacity estimates can result in policies which exacerbate existing differences. For example, using the utility based measurements, California may have the lowest utility estimated fiscal capacity not because its resource constraint is more limiting relative to other states, but because the state government is not spending in a way that maximizes the utility of its citizens. If its relative ranking is the result of less than optimum behavior, it could achieve a higher level of utility (and improve its "fiscal capacity") with a redistribution of 
existing resources between public and private goods, e.g., a movement from $\mathrm{U}_{2}$ at $A$ to $\mathrm{U}_{3}$ at $\mathrm{B}$, rather than with a grant. In reality this redistribution policy does not change the fiscal capacity or resource constraint facing California but only its value estimated on the basis of utility maximization. Obviously, to the extent that the fiscal capacities of California and other states are underestimated relative to other states, a system of grants to equalize fiscal capacity can result in greater, not less, inequality.

The assumption of utility maximization is standard in many studies, even though it may not describe reality perfectly. However, in the context of government budgeting there is a question of whose utility is maximized. Utility based estimates of fiscal capacity are based on the assumption that states " . . . act as decision units with the goal of maximizing the welfare of citizens," 11 but there is a sizable amount of literature which suggests that government budgets reflect the preferences of government bureacrats, most of whom are neither elected nor appointed publicly. Public choice theorists generally assume that bureaucrats seek to maximize their own utility functions subject to externally imposed constraints; further, such behavior is not necessarily consistent with the maximization of citizen welfare and can result in an oversupply of public goods. ${ }^{12}$ This view of oversupply is contrasted with the more traditional view that the public sector tends to underallocate resources for public goods because of the difficulties in articulating demand. ${ }^{13}$ Together these arguments strongly suggest that the budget making process is inefficient in maximizing the utility of its citizens and, consequently, the utility based fiscal capacity estimates are subject to the shortcomings described previously.

Even if the assumption of utility maximization is realized, the use of utility based estimates as the basis for an equity oriented policy can lead to deleterious results. Apart from theoretical considerations are those related to the specific data selected as proxies for the theoretical variables. Ideally, data which measure private and public expenditures and prices should be used to estimate the parameters of equation (4), but because such information, particularly with respect to prices, is not readily available imperfect measures must be substituted. Because it is sometimes necessary to select from a list of equally suitable proxies, the possibility exists that their substitution can result in substantially different estimates of fiscal capacity. Readily available state data were used to generate the original utility based estimates in order to demonstrate the feasibility of the utility approach in estimating fiscal capacity but other, at least equally suitable data could have been used. For example, the average monthly governmental wage might be estimated using either full time equivalents or total employment. Per capita private expenditures might be estimated better using per capita income rather than median family income divided by four; it defines income more comprehensively and is based on an estimate of population rather than the more arbitrary estimate of family size. Of course many other and better substi- 
tutions of data could be made, but these illustrated changes are meant to be instructive and not exhaustive. ${ }^{14}$

In order to test the sensitivity of the fiscal capacity estimates to the use of alternative data we first estimated three additional measures of fiscal capacity using the utility based methodology but substituting alternative empirical proxies. The four estimates shown in Table 2 include the original utility based estimates (Column 1) and three of our own (Columns 2-4). Our first estimate (Column 2), like those of the original utility based study, uses total public and private expenditures (median family income divided by four minus the average tax bill) per capita and median gross rent, but includes the number of full time equivalent employees (FTE) in estimating the average monthly governmental wage. ${ }^{15}$ Our second estimate (Column 3) differs from the first only in the replacement of total employees (TE) for full time equivalents. ${ }^{16}$ Our third estimate (Column 4) differs from the first in the substitution of per capita income of persons (IOP)for median family income divided by four. It appears that these substitutions change not only the magnitudes of the fiscal capacity estimates but also the rankings of the states (Table 2). In order to test these results for statistical differences we employed the Paired Comparison T-Test to each possible pair of estimates in Table $2 .{ }^{17}$ The results of this test (Table 3 ) indicate statistically significant differences at the 0.05 level for all tested comparisons and tend to support the hypothesis that the selection of a particular proxy appears to make a significant difference with respect to both the estimated absolute values of fiscal capacity as well as state rankings. These results imply that the selection of alternative proxy variables can influence substantially the effects of a specific policy.

\section{CONCLUDING COMMENTS}

Utility based estimates of fiscal capacity generate rankings which are substantially different from those using more conventional techniques. Additionally, they generate significantly different ranks when alternative empirical proxies are used to estimate the general model. That they can differ by such a magnitude serves to emphasize the importance of correctly specifying and estimating fiscal capacity. While the utility based estimates are developed more properly from economic theory than the more conventional estimates, their demonstrated sensitivity to alternative input data and the conceptual weaknesses of the methodology preclude their use as policy tools at this time. Further, basing policy on cardinal estimates of utility rather than conventional estimates of capacity is not likely to be anymore pleasing theoretically or politically.

The problem in developing generally accepted estimates of fiscal capacities stems, in part, from the difficulties in merging successfully the conceptual ideal with practical limitations. Conceptually fiscal capacity connotes a local tax collection limit which is determined by the extent to which the taxing unit can identify and tax its local tax base without eroding it. The local tax base is determined by the income (in the Haig-Simons sense) generated by residents as well as the ability to shift taxes to nonresi- 
TABLE 2

Value and Ranking by States of Alternative Fiscal Capacity Estimates

\begin{tabular}{|c|c|c|c|c|}
\hline State & $\begin{array}{c}(1) \\
\text { Original }\end{array}$ & $\begin{array}{c}(2) \\
\text { FTE }\end{array}$ & $\begin{array}{c}(3) \\
\text { Revised } \\
T E\end{array}$ & $\begin{array}{l}(4) \\
I O P\end{array}$ \\
\hline Alabama & $3570(16)$ & $3097(30)$ & $3389(37)$ & $3651(30)$ \\
\hline Alaska & $3425(40)$ & $3154(20)$ & $3415(34)$ & $3521(39)$ \\
\hline Arizona & $3183(49)$ & $2856(49)$ & $3200(48)$ & $3366(49)$ \\
\hline Arkansas & $3367(46)$ & $3029(40)$ & 3377 (39) & $3718(24)$ \\
\hline California & $3180(50)$ & $2860(48)$ & $3227(47)$ & $3475(45)$ \\
\hline Colorado & $3664(5)$ & $3239(11)$ & $3732(11)$ & $3846(10)$ \\
\hline Connecticut & 3520 (22) & 3287 ( 6$)$ & $3536(22)$ & 3953 ( 3$)$ \\
\hline Delaware & $3585(10)$ & 3385 ( 3 ) & $3587(20)$ & 3982 ( 2) \\
\hline Florida & $3276(47)$ & $2896(47)$ & $3123(50)$ & $3786(17)$ \\
\hline Georgia & 3608 ( 8) & $3276(7)$ & $3551(24)$ & $3890(7)$ \\
\hline Hawaii & $3719(3)$ & $3153(21)$ & $3459(30)$ & 3493 (43) \\
\hline Idaho & $3553(18)$ & $3201(15)$ & $3804(7)$ & $3751(20)$ \\
\hline Illinois & 3469 (29) & 3171 (19) & $3634(17)$ & $3331(46)$ \\
\hline Indiana & 3585 (11) & $3252(10)$ & $3698(14)$ & $3744(21)$ \\
\hline Iowa & 3579 (12) & $3112(28)$ & $3661(16)$ & $3657(28)$ \\
\hline Kansas & $3665(4)$ & $3221(12)$ & 3809 ( 6$)$ & $3931(5)$ \\
\hline Kentucky & $3371(45)$ & $2971(45)$ & $3319(45)$ & $3544(35)$ \\
\hline Louisiana & $3461(31)$ & $3080(33)$ & $3400(36)$ & 3549 (34) \\
\hline Maine & $3428(37)$ & $3144(23)$ & $3682(15)$ & 3624 (32) \\
\hline Maryland & $3625(6)$ & 3244 ( 9$)$ & 3418 (33) & $3817(12)$ \\
\hline Massachusetts & 3573 (13) & $3313(44)$ & 3588 (19) & 3862 (9) \\
\hline Michigan & $3422(41)$ & 3030 (39) & $3517(28)$ & $3465(46)$ \\
\hline Minnesota & $3480(28)$ & $2982(4)$ & $3553(23)$ & $3411(48)$ \\
\hline Mississippi & $3507(25)$ & $3190(17)$ & $3350(43)$ & $3533(37)$ \\
\hline Missouri & $3514(24)$ & 3132 (26) & $3424(25)$ & $3796(16)$ \\
\hline Montana & $3526(21)$ & 3203 (14) & $3715(12)$ & $3736(22)$ \\
\hline Nebraska & $3458(34)$ & $2965(46)$ & $3700(13)$ & $3802(14)$ \\
\hline Nevada & $3527(20)$ & $3142(25)$ & $3441(31)$ & 3778 (18) \\
\hline New Hampshire & $3730(2)$ & $3410(2)$ & 4371 ( 2$)$ & $3940(4)$ \\
\hline New Jersey & $3518(23)$ & $3268(8)$ & $3615(18)$ & $3881(8)$ \\
\hline New Mexico & $3439(36)$ & $3022(41)$ & $3403(35)$ & 3481 (44) \\
\hline New York & $3399(44)$ & $3107(29)$ & $3373(40)$ & 3810 (13) \\
\hline North Carolina & $3263(48)$ & $2837(50)$ & $3134(49)$ & $3756(19)$ \\
\hline North Dakota & 3426 (39) & $3043(36)$ & $4282(1)$ & $3517(40)$ \\
\hline Ohio & $3611(7)$ & $3298(5)$ & $3785(9)$ & $3827(11)$ \\
\hline Oklahoma & $3573(15)$ & $3129(31)$ & $3574(41)$ & $3916(23)$ \\
\hline Oregon & $3421(42)$ & 3049 (37) & $3522(26)$ & $3663(27)$ \\
\hline Pennsylvania & $3448(35)$ & $3070(34)$ & $3380(38)$ & 3649 (31) \\
\hline Rhode Island & $3468(30)$ & 3209 (13) & 3521 (27) & 3800 (15) \\
\hline South Carolina & 3541 (19) & 3094 (32) & 3479 (29) & $3529(38)$ \\
\hline South Dakota & 3489 (27) & 3967 (22) & $3676(4)$ & $3147(26)$ \\
\hline Texas & $3573(14)$ & 3095 (27) & $3361(21)$ & $3729(6)$ \\
\hline Utah & $3600(9)$ & 3182 (18) & $3844(5)$ & $3501(42)$ \\
\hline
\end{tabular}


TABLE 2 (Cont.)

\begin{tabular}{|c|c|c|c|c|}
\hline State & $\begin{array}{c}\text { (1) } \\
\text { Original }\end{array}$ & $\begin{array}{l}\text { (2) } \\
\text { FTE }\end{array}$ & $\begin{array}{c}(3) \\
\text { Revised } \\
T E\end{array}$ & $I O P$ \\
\hline Vermont & 3497 (26) & $3143(24)$ & $3792(8)$ & $3614(33)$ \\
\hline Virginia & $3462(33)$ & $3045(35)$ & $3336(44)$ & 3694 (25) \\
\hline Washington & 3464 (32) & $2983(43)$ & 3428 (32) & $3544(36)$ \\
\hline West Virgina & $3427(38)$ & $3010(42)$ & $3360(42)$ & $3510(41)$ \\
\hline Wisconsin & $3556(17)$ & $3197(16)$ & $3756(10)$ & $3435(47)$ \\
\hline Wyoming & $3774(1)$ & $3575(1)$ & 4078 ( 3$)$ & $4171(1)$ \\
\hline
\end{tabular}

dents. In a dynamic world this tax base is likely to fluctuate due to changes in the various factors which affect local income generation, and at some point it is not unreasonable to expect that higher tax rates will lead to lower tax collections. Ideally, then, an estimate of maximum local revenue collections would be generated within the context of a general equilibrium model. In practice, however, lack of data has resulted in a variety of so-called fiscal capacity estimates which, with the exception of the utility based estimates, are based generally on some concept of average taxing behavior. And while the utility based approach represents an admirable attempt to focus debate more properly on the true nature of local fiscal constraints, it too falls short of the conceptual ideal.

TABLE 3

Results of Paired Comparisons T-Test

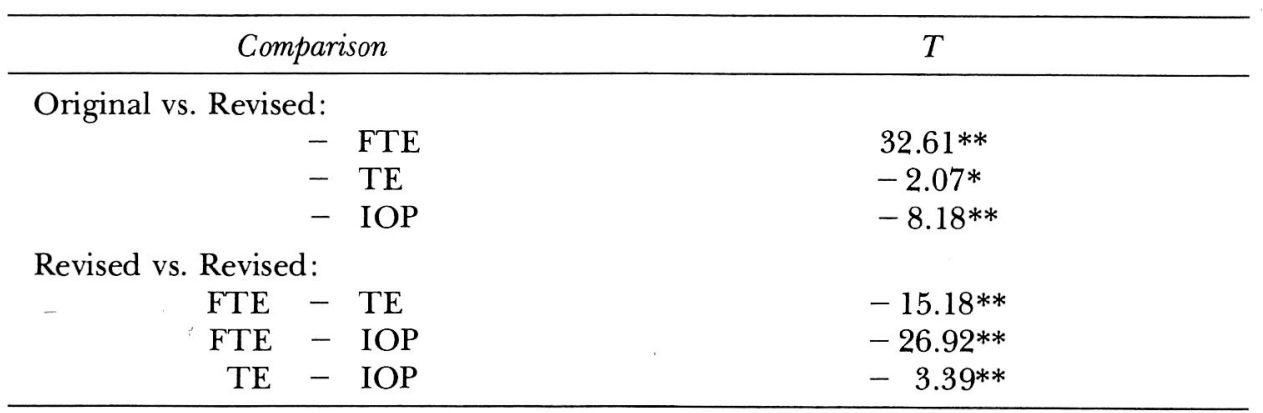




\section{FOOTNOTES}

${ }^{1}$ Advisory Commission on Intergovernmental Relations, Measuring the Fiscal Capacity and Effort of State and Local Areas, Washington: U. S. Government Printing Office, March, 1982, p. 7.

${ }^{2}$ Ibid., p. 11.

3John Akin, "Fiscal Capacity and the Estimation Method of the ACIR," National Tax Journal, May, 1973, p. 277.

See, for example, John Akin, "An Improved Method for Estimating Local Fiscal Capacity" Review of Regional Studies, Fall, 1974, pp. 29-43.

John Akin, "Estimates of State Resource Constraints Derived from a Specific Utility Function: An Alternative Measure of Fiscal Capacity," National Tax Journal, March, 1979, pp. 61-71.

\%elen F. Ladd, "Local Education Expenditures Fiscal Capacity and the Composition of the Property Tax Base," National Tax Journal, June, 1975, pp. 145-148.

${ }^{7}$ Akin, op. cit., p. 64

${ }^{8}$ Akin, op. cit., p. 64 .

${ }^{8}$ This alternative was selected because its estimates, like those of the utility based approach, are based on 1969 data.

${ }^{19}$ Gilbert Reilly, "Estimates of State Resource Constraints Derived from a Specific Utility Function: An Alternative Measure of Fiscal Capacity: A Comment," National Tax Journal, December, 1980, pp. 505-506.

${ }^{11}$ A kin, op. cit., p. 65

${ }^{12}$ This argument was developed originally by William Niskanen in Bureaucracy and Representative Government, New York: Aldine, 1971. Since then there have been many other publications which express a similar view, including Borchending, T. (ed.), Budgets and Bureaucrats: The Sources of Government Growth, Durham: Duke Uni- versity Press, 1977, Breton, A. and Wintrobe, R., "The Equilibrium Size of a Budget - Maximizing Bureau,' Journal of Political Economy, 83(1), 1975, Downs, George and Larkey, Patrick, "Theorizing About Public Expenditure Decision-Making," Policy Sciences, 11(2), 1979, McQuire, T., Coiner, M., and Spancake, L., "Budget Maximizing Agencies and Efficiency in Government," Public Choice, 34(3-4), 1979, and Niskanen, W. "Bureaucrats and Politicians," Journal of Law and Economics, 18 (3), 1975.

${ }^{13}$ The literature is well known and includes classics Tike Samuelson, Paul, "The Pure Theory of Public Expenditure," Review of Economics and Statistics, November, 1954, and Buchanan, J. and Tullock, G., The Calculus of Consent, Ann Arbor: University of Michigan Press, 1962.

${ }^{14}$ We would like to thank an anonymous referee for pointing out that the selection of particular proxies may bias the results toward certain states, e.g., the use of median gross rent may bias the price figure for private goods upwards in highly urban states relative to rural states.

${ }^{15}$ A kin, ibid., p. 68.

${ }^{16} \mathrm{We}$ cannot tell precisely what data Akin used to estimate the monthly governmental wage because he did not list his sources. However, our estimate of $\$ 492$ for the state of California is sufficiently different from that reported by Akin (\$726) to indicate the use of different data.

${ }^{17}$ We also used the Wilcoxan Matched Pairs Signed Rank test with similar results. The $\mathrm{Z}$-values for the respective pairings listed in Table 3 are $8.00,-0.67,-5.05$, -7.72 , and 8.47 . With the exception of the second comparison all are statistically significant at the 0.01 level. 